\title{
A Ascensão Política dos Pentecostais no Brasil na Avaliação de Líderes Religiosos*
}

\author{
Maria das Dores Campos Machado \\ Joanildo Burity ${ }^{2}$ \\ ${ }^{1}$ Professora-associada da Universidade Federal do Rio de Janeiro (UFRJ), Rio de Janeiro, \\ Brasil. E-mail: mddcm@uol.com.br. \\ ${ }^{2}$ Pesquisador-titular, diretor de formação e desenvolvimento profissional na Fundação \\ Joaquim Nabuco, Recife, Pernambuco, Brasil. E-mail: joanildo.burity@fundaj.gov.br.
}

\section{INTRODUÇÃO}

- mbora a politização dos pentecostais não seja uma especificidade Wilson, 1997; Freston, 2004; entre outros), nas últimas décadas o país tem se destacado entre as sociedades latino-americanas pela importância crescente da ação direta de religiosos e membros de comunidades pentecostais na arena política. Com grande capacidade de mobilização popular, as igrejas conseguem eleger representantes não só para as Casas Legislativas municipais e estaduais, como também para o Congresso Nacional, onde atualmente ocupam 12\% das cadeiras da Câmara Federal e integram a Frente Parlamentar Evangélica (Machado, 2012).

Neste artigo, apresentamos uma análise do processo de revisão das posições tradicionais dos pentecostais em relação ao engajamento político e à participação nos debates públicos sobre as questões sociais e éticas da sociedade brasileira, a partir de uma pesquisa qualitativa com

\footnotetext{
* Agradecemos o apoio financeiro do Pentecostal and Charismatic Research Initiative (PCRI) da University of Southern California ao projeto de pesquisa Pentecostal Leaders in Latin America, sem o qual a pesquisa que fundamentou este trabalho não teria sido possível. Somos gratos também ao Conselho Nacional de Desenvolvimento Científico e Tecnológico (CNPq) pela concessão de bolsas - Iniciação Científica e de Produtividade em Pesquisa - a Maria das Dores Campos Machado e seus alunos.
}

DADOS - Revista de Ciências Sociais, Rio de Janeiro, vol. 57, no 3, 2014, pp. 601 a 631. 
importantes líderes deste segmento religioso. O objetivo principal é conhecer a visão de atores religiosos que formam opinião pública no meio pentecostal em relação a uma série de temáticas sociais, políticas e econômicas nos planos mundial e nacional. Interessava-nos particularmente recolher as opiniões e iniciativas dos líderes nas áreas cultural/identitária (com temas como aborto, homossexualidade, questões de gênero etc.) e política (partidos, corrupção, eleições etc.).

Foram realizadas entrevistas com 58 lideranças que, na ocasião da pesquisa (2011-2012), desenvolviam atividades nas cidades de Salvador, São Paulo, Belo Horizonte, Brasília, Campinas e Rio de Janeiro. Quase todos tinham cargo eclesiástico - pastores(as), missionários(as), bispos, presbíteros - e 18 entrevistados do sexo masculino acumulavam ou haviam se licenciado de seu cargo na igreja para assumir uma cadeira na Câmara Federal, nas Assembleias Legislativas ou nas Câmaras Municipais das cidades listadas anteriormente. Os demais eram pastores que dirigiam instituições assistenciais e assessores políticos com atuação no Congresso Nacional. A maioria é pentecostal, mas também foram entrevistados alguns líderes de segmentos das igrejas históricas que se pentecostalizaram nas últimas décadas ${ }^{1}$.

Inicialmente, apresentamos um breve apanhado das principais alterações no campo cultural, chamando atenção para as relações dessas mudanças com processos em curso nas outras esferas da sociedade brasileira. Em seguida, examinamos as opiniões das lideranças pentecostais no que diz respeito à política e à representação do segmento religioso no sistema político, em especial no Legislativo. Na seção seguinte, discutimos a percepção desses entrevistados em relação ao comportamento parlamentar dos políticos com identidade pentecostal. Â guisa de conclusão, procuramos demonstrar como a participação na esfera da política se tornou fundamental para esse grupo religioso que, embora em expansão, é minoritário e se sente discriminado na sociedade civil e no sistema político brasileiro.

Argumentamos que, para os pentecostais, a participação no Poder Legislativo é interpretada a partir de dois vetores principais: a) como forma de sobrevivência em uma ordem social em que as relações entre o Estado e os grupos religiosos sempre foram muito assimétricas e onde a agenda política dos movimentos feministas e pela diversidade sexual vem se impondo e orientando as políticas públicas no campo da educação, da saúde e das relações familiares; b) como forma de cons- 
trução (minoritária) de uma agência coletiva com pretensões de reconhecimento e influência. Nesse segundo registro, autoconfiança e uma certa maneira de pensar estrategicamente o alcance desses objetivos se combinam ou respondem ao sentimento de insegurança que o discurso da sobrevivência expressa.

A figuração discursiva que articula a percepção de "ter que fazer política" será explorada por dois ângulos: o de uma "resposta" ao desafio das mudanças políticas e socioculturais informadas pela crescente pluralização da vida social no Brasil pós-transição, mas também no contexto globalizante; e o de uma tentativa de construir um "projeto" cujos contornos permanecem tão indefinidos para a maioria dos pentecostais quanto suscitam fantasmas de "constantinismo" 2 para seus adversários e críticos. A articulação da modalidade "minoritizante" será explorada nesse segundo registro.

\section{MUDANÇAS RECENTES NO CAMPO CULTURAL E POLÍTICO BRASILEIRO}

As últimas quatro décadas foram marcadas não só pelo processo de redemocratização do país mas também pela presença no poder político dos partidos de centro e de esquerda e pela política de aproximação do Estado brasileiro com os movimentos sociais que buscavam reconhecimento na sociedade. De início, o restabelecimento da ordem democrática suscitou em diferentes setores sociais uma grande expectativa de revisão da cultura política do país, interpretada pelos especialistas como personalista, autoritária e clientelista (Sorj, 2006; Carvalho, 2000; Burity, 2002; Baquero, 2003), e de criação de novas formas de participação popular e de gestão da coisa pública (Burity e Andrade Jr., 2011). Avanços importantes foram realizados, em especial na área dos direitos humanos e na ampliação dos segmentos que integram a elite política, mas não ocorreu uma transformação substancial da cultura política nacional, como veremos nas páginas seguintes.

A composição religiosa da população brasileira também sofreu alterações neste período, verificando-se um acelerado trânsito de fiéis em direção aos grupos evangélicos ${ }^{3}$. Isto é, enquanto a representação dos católicos na população brasileira declinou de 83,3\%, em 1991, para $73,8 \%$, em 2000, e 64,6\%, em 2010, a dos evangélicos, nos mesmos períodos, evoluiu de $9 \%$ para 15,6\% e 22,2\% (IBGE, censo demográfico de 2010). Deve-se esclarecer que essa tendência ascendente resulta da diversificação e da difusão do pentecostalismo, uma vez que os integran- 
tes desse segmento deixaram para trás os chamados protestantes históricos, nas últimas décadas do século XX, e, segundo os dados do último censo, representam agora $60 \%$ dos evangélicos.

Essa surpreendente multiplicação e diferenciação de grupos pentecostais encontra-se relacionada, segundo a literatura nacional, com a revisão da posição de apartamento da cultura e da política partidária brasileira que predominara durante grande parte do século XX. No campo da cultura, os analistas (Birman, 2003; Mariano, 2000; Machado, 2006) identificam entre as mudanças mais significativas: a flexibilização dos usos e costumes; a adoção da Teologia da Prosperidade; a capacidade de selecionar e incorporar elementos da agenda política de movimentos sociais; e os investimentos crescentes nos meios de comunicação eletrônicos. No campo da política, vários estudos (Burity e Machado, 2006; Machado, 2003; Fonseca, 2008; Freston, 2008; Campos, 2010; Mariano, 2005) salientam a aproximação dos atores religiosos com os partidos políticos; a ampliação da presença de líderes religiosos no Legislativo; e o interesse tanto pelas concessões de canais de televisão e de rádio, quanto pelas parcerias com as agências governamentais na área da ação social.

Impulsionando o processo de mutação no universo evangélico, estavam as igrejas neopentecostais que surgiram a partir da década de 1970 e atraíram milhares de fiéis pela estratégia de enfatizarem a prática do exorcismo, a capacidade de cura e a resolução de problemas econômicos e familiares em seus programas televisivos. Já a Teologia da Proposperidade promoveu um deslocamento das expectativas milenaristas de salvação para uma vida de graças no presente, e favoreceu a inserção dos pentecostais na política partidária, no mercado editorial e no restrito universo das telecomunicações (Corten et al., 2003).

De um ponto de vista mais estritamente político, pode-se mencionar o impacto da mobilização social nos últimos anos da ditadura militar, facilitada pela relativa liberalização do regime (retorno ao pluripartidarismo, restabelecimento do calendário eleitoral com exceção da Presidência da República, diminuição da repressão ao movimento sindical e aos movimentos sociais populares). Esse impacto significou pelo menos três coisas para o pentecostalismo: a) a percepção de uma oportunidade de sair da invisibilidade e reclamar o acesso à esfera pública institucional que outros setores emergentes começavam a ter; $b$ ) a emergência de uma agência interna empurrando para a publicização 
como caminho para a saída da condição de minoria política e culturalmente subalternizada, e questionando o apoliticismo; c) a confrontação com os setores mais "avançados" dos movimentos sociais movimento feminista, negro, ambientalista e LGBT (Lésbicas, Gays, Bissexuais, Travestis, Transexuais e Transgêneros) - e com o mundo da esquerda partidária, cujas bandeiras desafiavam a autocompreensão pentecostal da política e da participação social.

Um estudo quantitativo (Fernandes et al.,1998) realizado na década de 1990, com fiéis de igrejas históricas e pentecostais da Região Metropolitana do Rio de Janeiro, já chamava a atenção para o fato de que, embora apresentassem a mesma tendência de pequena participação em associações e instituições civis dos brasileiros em geral, os evangélicos procuravam mais os políticos para fazer pedidos, sugestões ou reclamações dos que os não evangélicos. Ou seja, os fiéis evangélicos demonstravam um sentimento mais forte do que o restante da população brasileira de que possuíam os seus representantes e tinham "com quem falar no distante mundo da política". A pesquisa indicava também que, apesar de acompanhar os programas de propaganda eleitoral gratuita, a atividade desenvolvida pela maioria dos entrevistados era a realização de orações por seus candidatos. Detectou, entretanto, que os pentecostais tendiam a um maior engajamento nas atividades tradicionais da militância política do que os evangélicos históricos, com destaque para os fiéis da Igreja Universal do Reino de Deus (IURD) que não só participavam mais da discussão política na Igreja, como também eram os que proporcionalmente mais declaravam ter afixado cartazes dos candidatos em suas casas (Fernandes et al., 1998:123).

Outra constatação interessante daquela pesquisa foi a de que o fato de o candidato apresentar "boas ideias políticas" aparecia na frente da identidade religiosa entre os princípios para a definição dos votos, sugerindo um maior "reconhecimento da autonomia e das características próprias da política" por parte dos evangélicos históricos. De qualquer forma, $40 \%$ dos entrevistados evangélicos valorizava "a crença religiosa do candidato" e este princípio tendia a ser ainda mais importante entre os fiéis da IURD (acima de 50\%), que em sua grande maioria também declaravam canalizar seus votos para as candidaturas saídas dos próprios quadros da igreja (95\%) (ibidem:126).

Estudos qualitativos demonstrariam posteriormente que muitas das tendências identificadas nesta pesquisa poderiam ser constatadas nas 
comunidades evangélicas de outras unidades da Federação brasileira, e que a histórica rejeição dos grupos pentecostais pela política fora superada. De forma bem sintética, nas últimas décadas o Pentecostalismo tornou-se uma religião pública, e um dos fatores mais importantes nesse processo talvez tenha sido a adoção de um modelo corporativo de representação política, com o lançamento de candidaturas oficiais por parte da IURD. Esse tipo de iniciativa ampliou a força política do grupo e, consequentemente, acirrou as disputas no interior do campo evangélico fazendo com que outras igrejas criassem espaços de debate, socialização e organização das iniciativas no campo da política eleitoral (Freston, 1999; Corten et al., 2003; Machado, 2006; Campos, 2010). A Assembleia de Deus (AD) - a maior denominação pentecostal -, a Igreja do Evangelho Quadrangular e outras começaram a imitar a IURD na produção de materiais, realização de reuniões de orientação para os candidatos e apresentação de suas respectivas plataformas políticas, e engajamento em negociações com os dirigentes partidários de todo o espectro político (cf. Oro, 2010, 2011; Burity e Machado, 2006).

Deve-se registrar ainda que, desde as décadas de 1980 e 1990, observa-se um grande interesse dos partidos políticos brasileiros pelos pentecostais, com as lideranças partidárias estimulando filiações e candidaturas de atores religiosos desse campo na expectativa de ampliarem suas chances de sucesso nas urnas. Essa lógica pragmática acabou favorecendo não só a entrada dos pentecostais na política institucional, como também na direção das máquinas partidárias. Assim, a interpenetração das esferas confessional e partidária, que já havia sido identificada na década de 1980 com a participação de religiosos da IURD nos diretórios estaduais do Partido Liberal (1985-2006), pode ser ainda hoje constatada quando se examina a composição das bancadas e das executivas do Partido Republicano Brasileiro (PRB) e do Partido Social Cristão (PSC) $)^{4}$

Este fenômeno da crescente participação dos pentecostais nas agremiações partidárias e nas Casas Legislativas introduz novos desafios para as ciências sociais e, em particular, para a sociologia da religião. Afinal, como compreender a construção dessa agência política pentecostal responsável por um novo modelo de religião pública acoplado a um processo de emergência de uma voz minoritária? Que concepções da política e do seu lugar na esfera pública possuíam esses pentecostais? De que modo se expressam internamente essas concepções e que 
práticas elas incorporam e autorizam? Nas próximas seções, discutiremos essas questões a partir do material empírico já mencionado.

\section{A POLÍTICA NA VISÃO DOS PENTECOSTAIS}

A politização religiosa em curso nas sociedades ocidentais tem se defrontado com três ordens de suspeição: a) a (re)introdução "indevida" da lógica e da linguagem de organizações religiosas no cenário da política institucional; b) seu conteúdo conservador do ponto de vista ideológico; c) seu potencial intolerante, que criaria problemas de coesão social onde já há suficientes desafios colocados pela pluralidade sociocultural existente (Casanova, 1994, 2010; Cannell, 2010).

Tais referências são heuristicamente fundamentais para a compreensão dos impactos dos discursos pentecostais na cultura política. A desconfiança de que haja um estreitamento da esfera pública, com ameaças a expectativas de avanço das demandas por justiça, igualdade e reconhecimento vindas de grupos subalternos, produz uma reticente admissão do maior espaço ocupado pelos novos atores da religião pública. Por outro lado, uma complexa teia de justificativas para esses temores e resistências à "política religiosa" é tecida de parte a parte, onde estereótipos sobre as minorias emergentes e reiteração de mitologias de unidade nacional, neutralidade do Estado e pluralismo cultural ameaçado se justapõem de forma heteróclita e alimentam confrontos entre maiorias e minorias, ou, no caso específico, também entre minoria religiosa e outras politicamente emergentes (mulheres, negros, gays etc.).

Uma marca preliminar importante a ressaltar é que nossos entrevistados são fluentes no "idioma secular". Conseguem perfeitamente expressar visões, narrar acontecimentos, defender posições, identificar tendências estruturais, sem recorrer a uma linguagem cifrada pela religião. Em determinados debates, como os ligados à sexualidade e à manipulação genética, discursos científicos, psicológicos e jurídicos são crescentemente identificáveis, contra e a favor, dependendo do ator religioso em questão. Esse ponto aparentemente banal tem grande relevância no debate recente sobre a presença da religião na esfera política. Seja no registro acadêmico, seja no debate público, há expressas resistências ao que pareceria uma indevida intrusão de argumentos religiosos na esfera pública, precisamente porque eles apelariam a critérios não verificáveis ou não acessíveis a outsiders. 
Desde os liberais a Rawls, que consideram imprópria toda manifestação de "doutrinas abrangentes" nas esferas de debate e tomada de decisões públicas (cf. Dombrowski, 2001), aos habermasianos que entendem ser preciso uma "tradução" em linguagem secular do discurso religioso (cf. Habermas, 2008), há resistências contra o uso público da linguagem religiosa. Os pentecostais não exigem, entretanto, admissão de valores transcendentais como condição de interação e debate com outros interlocutores religiosos ou seculares, nem precisam de tradutores para adentrarem os protocolos de discussão pública, como sugere Habermas.

Quando perguntados sobre diferentes temas, a esmagadora maioria dos entrevistados não apresenta dificuldades em transitar de um registro discursivo a outro - ou seja, da religião ao campo temático em tela. Este não é o problema. Eles utilizam um léxico "secular": eleições, políticas públicas, justiça social, direitos humanos, família, política internacional, relação religião-Estado etc. Com elevado grau de instrução, os entrevistados adotam argumentos "acadêmicos", ao saberem que se trata de uma situação de entrevista e que, dependendo das perguntas, se espera que demonstrem conhecimento da (sua) realidade, estilo analítico e reflexividade.

Além disso, a orientação religiosa não se sobrepõe inteiramente à forma de articular temas sociais, políticos e culturais. Em outras palavras, por mais que se trate de entrevistados profundamente imbuídos de uma identidade religiosa, o que é distintivo de suas perspectivas não é uma maneira sui generis de enquadrar os temas sociais e políticos. Não é exatamente quanto ao conteúdo das afirmações sobre esses temas que se revela o lugar a partir do qual falam esses atores. Despidos de referências biográficas e contextuais, muito do que dizem passa perfeitamente por argumentos articulados desde outras posições enunciativas no cenário nacional, inclusive inteiramente seculares. Vale ressaltar, nesse sentido, que a cultura política do pentecostalismo não é um caso à parte em relação a coordenadas mais amplas do que a referência religiosa. Há muitas semelhanças com a cultura política "secular", nas virtudes e nos vícios. O específico é um modo de articular o "secular" e o "religioso" ou o "espiritual", que produz um caso de dupla hermenêutica ${ }^{5}$ : a realidade se desdobra numa textura multidimensional, com fenômenos "perfeitamente seculares" se revestindo de significado religioso ou eventualmente autorizando certas interpretações "para dentro" da comunidade de fé que não se aplicam ou não são utilizadas 
"para fora". Trata-se de uma dupla hermenêutica, porque os acontecimentos são religiosos $e$ seculares para os pentecostais, ainda quando são apenas seculares para os atores não religiosos (ou não pentecostais, quando há disputas com outros atores religiosos, por exemplo os ecumênicos ou os de matriz africana).

É possível identificar, na fala dos entrevistados, uma narrativa que vai da admissão de um quietismo apoliticista ou sectário até uma aberta defesa da politização entre os pentecostais. Ela por vezes se articula em termos geracionais, ora em termos de uma minoria que se percebe em expansão (e vivendo um descompasso entre sua autopercepção e seu reconhecimento social) e reclama direitos, por vezes as duas coisas. Uma liderança nacional do pentecostalismo brasileiro afirmou-nos que sua "geração foi criada e aprendeu com os pais o seguinte: 'Igreja é de Deus, política é do cão, é do diabo, e é evidente que uma coisa não se mistura com a outra!'". Mas a visão atual deste líder é bem distinta desta repulsa ao mundo político ensinada por seus antepassados. Segundo suas palavras, "nós somos alguns milhões de brasileiros e, como qualquer outro, pagamos impostos. Então, por que não fazer parte do governo? Também temos os nossos direitos".

Por outro lado, ela emerge em algumas das entrevistas de modo mais consistente que em outras. Não está presente em todas. É possível indicar que quanto mais jovem é o(a) entrevistado(a) ou mais recente seu envolvimento com a politização pentecostal, menor a presença e densidade dessa narrativa. Essa construção discursiva é complementada por histórias pessoais de trajetórias políticas em que se cruzam as dificuldades de construir uma representação pela via eleitoral, quando a maioria dos evangélicos rejeitava a política nos termos indicados, e as mudanças recentes. Nesses casos, percebe-se também a ausência de pentecostais entre os poucos parlamentares evangélicos eleitos antes de meados de 1980. Além disso, já se determina uma característica marcante do que viria a ser a política pentecostal: o papel central das lideranças, notadamente pastores, como gatekeepers do eleitorado. Esse papel revela tanto a inadequação de se falar de automobilização de massas pentecostais como a dimensão fortemente estratégica da intervenção pentecostal na política e a relativização do "carisma individual" da maioria dos políticos em favor da política corporativa da Igreja (Oro, 2003; Burity, 2006a).

Há também outro modelo de politização que não se materializa enquanto política eleitoral. Trata-se da militância social de pentecostais, 
que também emergiu em larga medida no contexto da democratização recente do país ${ }^{6}$. Essa militância articula outra concepção da política e outra lógica de representação. Ela pensa-se como e a partir da sociedade civil, como compromisso cotidiano com os setores subalternos, particularmente no atendimento a necessidades materiais dos pobres e, dependendo da radicalidade desse compromisso, articulando as linguagens dos direitos e do associativismo civil. A representação se vê como expressão pública de uma presença evangélica nas lutas sociais "desde baixo". A política é, antes de tudo, construção de um modelo alternativo de sociedade (embora pouco semelhante ao discurso da teologia da libertação). Não há aqui preferências pela via eleitoral, nem grandes simpatias pela ideia das candidaturas evangélicas. Em alguns casos, essa posição se expressa através da participação em entidades sociais ou de serviço evangélicas. Em outros, o impacto sobre indivíduos pentecostais dos intensos processos de mobilização social das décadas de 1970 a 1990 explica sua politização segundo esse modelo. Uma assessora da Câmara Federal exemplifica bem essa trajetória de militância social:

Quando fiz pedagogia, eu já militava na educação social. Fui funcionária da Visão Mundial muitos anos (...). Então já trabalhava com educação social. Até que eu me descobri jurista, quando fui fazer mestrado (...) eu fiz paralelo um curso de direito. Fiz apenas para entender a ligação entre o menino de rua e a penalidade. Estavam construindo o Estatuto da Criança e do Adolescente [ECA], fiz parte do movimento nacional dos meninos de rua, e a gente estava ajudando nesse momento da Constituinte [1987-1988], a construção do ECA, e eu precisava entender um pouco a questão jurídica. E aí fui para a área jurídica. (...) Muito cedo participei de movimentos sociais. Fui do movimento estudantil, fui do movimento sem teto no início da sua configuração, quando não era tão político, e o movimento nacional de meninos de rua.

Recorrentemente, esses militantes sociais enfrentaram a incompreensão, a falta de apoio ou mesmo a oposição frontal de suas igrejas, o que em muitos casos gerou uma circulação por outros espaços eclesiais estimulando uma espécie de "ecumenismo de base" evangélico.

Sinteticamente, pode-se dizer que a disputa pelo sentido da política e do que ela representa para os evangélicos recentemente politizados tem favorecido o questionamento sobre as convicções e credenciais democráticas dos pentecostais. Muitas das críticas feitas ao pentecostalismo como religião pública apontam para o autoritarismo no exercício 
da liderança nas próprias igrejas - seja o estilo caudilhesco de seus pastores locais, seja a estrutura fortemente hierarquizada (e crescentemente episcopal) das denominações pentecostais - e para a fragilidade ética tanto dos parlamentares quanto das lideranças eclesiásticas, respectivamente, no exercício de sua função pública ou de suas demandas e negociações políticas.

Há, de fato, uma frágil articulação do tema democrático, se por isso se entende o veio cívico-republicanista da participação cidadã e da defesa da coisa pública, ou as formulações em termos de democracia participativa ou deliberativa. Mas os pentecostais possuem, sim, um grau de compromisso e de compreensão da democracia que, curiosamente, os aproxima de uma visão liberal. Jamais são postos em dúvida valores e instituições como a liberdade de expressão e de consciência, a organização pluripartidária da disputa política, o voto como meio de expressão de demandas à ordem política. Há, além disso, uma modulação welfarista desse liberalismo, com ampla aceitação da função (ou provisão) social estatal e uma certa rejeição do antiestatismo neoliberal, ainda que se mantenha uma maciça aceitação de vários outros aspectos dessa ideologia, como o estímulo ao empreendedorismo individual, o discurso da "responsabilidade" como contraponto aos direitos e a ideia de prosperidade material como expressão legítima da benção divina, que se traduz em amplo apoio às estruturas de mercado (Burity, 2006b, 2013).

Na linha da visão crítica da qualidade da política nacional que apresentamos acima, alguns entrevistados ponderam sobre as imperfeições da democracia brasileira: "a nossa democracia é ainda muito jovem. Ela ainda carece de muitos aperfeiçoamentos, principalmente na área da representação, na área da participação da sociedade nas decisões. Cada vez mais a nação está distanciada realmente das classes políticas." No entanto, essa percepção não autoriza, em nenhuma das entrevistas realizadas, um juízo genérico de rejeição da democracia. Esta fala, por exemplo, provém de um parlamentar com longa experiência, tradicionalmente posicionado na centro-direita do espectro ideológico. Ao contrário, há reiteradas intenções de contribuir para seu aperfeiçoamento. E em alguns casos, tanto de representantes do modelo parlamentar como do modelo de militância social que apresentamos anteriormente, se expressa a ideia de que somente a pressão organizada da sociedade vai conseguir romper a inércia e o autointe- 
resse dos políticos na manutenção das deficiências existentes e ajudar a aprofundar a democracia brasileira.

Especialmente no discurso dos parlamentares, defendemos que as posições conservadoras dos evangélicos em temáticas como direitos sexuais e reprodutivos e combate à homofobia não devem ser necessariamente compreendidas como ataques à democracia. Antes, tratar-se-ia mesmo de sua expressão: o embate agonístico é real, mas a lealdade a instituições e procedimentos democráticos em geral não está em questão. Além disso, entendemos que, no contexto democrático, parte do embate agonístico se refere a diferentes concepções do que seja democrático (por exemplo, se deve prevalecer a ativação do princípio da maioria ou o respeito às demandas e direitos das minorias, se as decisões devem ser ancoradas na participação e consulta direta ou na representação). Nos embates com seus adversários, os pentecostais conservadores entrevistados apelaram alternadamente para todos esses entendimentos.

A questão do agonismo democrático de forma alguma aparece para os pentecostais como um estorvo ou algo que desqualifique a democracia, nem queremos sugerir que seu engajamento agonístico os torna necessariamente campeões das demandas populares de base, pois é clara a predominância de concepções e práticas conservadoras de democracia. No entanto, talvez possamos dizer que, profundamente imbuídos de uma cultura na qual as diatribes doutrinárias e a postura conversionista predominam, não é preciso muito no processo de politização para que estas práticas sejam transformadas em recursos do agonismo democrático. A motivação "bíblica" apontada pelos pentecostais para a defesa de suas posições é complementada frequentemente pela articulação em termos de "moralidade pública" e de evidência produzida por surveys de opinião pública, que são perfeitamente adjudicáveis por parte de discursos não religiosos. Nisso também os conflitos recentes entre movimentos sociais e pentecostais nos debates citados podem obscurecer a extensão da adesão ao "liberalismo" na cultura política pentecostal contemporânea.

É interessante como um pequeno veio dessa afirmação democrática chega mesmo a articular um discurso laico sobre a responsabilidade do Brasil no cenário global na defesa dos direitos humanos e da democracia. Segundo um pastor pentecostal e deputado estadual no sudeste brasileiro, o Brasil está, comparativamente, à frente de muitas sociedades na questão dos direitos humanos, e tem a responsabilidade de arti- 
cular uma alternativa econômica e "humana" ao modelo prevalecente naqueles países e em outros. Valoriza-se a capacidade das instituições democráticas brasileiras de enfrentar as clivagens étnicas e religiosas (em comparação com as dificuldades da Índia em fazê-lo, por exemplo).

Colocar a questão da democracia a partir da perspectiva do pentecostalismo (enquanto religião protestante) implica, tanto no debate acadêmico como no discurso dos atores sociais e políticos brasileiros, reabrir a discussão sobre a relação entre religião e Estado. Embora isso ocorra muitas vezes nos termos exageradamente normativos de uma discussão sobre a legitimidade da relação entre religião e política tout court, especialmente nos discursos externos e internos críticos da presença pentecostal na política nacional, é a relação entre religião e Estado que está em jogo. Afinal, todos admitem que não é (mais) possível ignorar a imbricação entre religião e política. Estamos em definitivo no contexto da religião pública, ativado pela emergência de uma minoria religiosa fortemente mobilizada em torno da autopercepção tanto de seu peso numérico e de sua representatividade sociocultural como dos entraves ao seu reconhecimento em setores importantes do Estado e da sociedade.

A política emerge nesse contexto como uma estratégia de sobrevivência, que se traduz em vários sentidos, a nosso ver, em termos hegemônicos. Precisamos explicar nossa posição. Em que sentido "sobrevivência" (traduzida como um "ter que fazer política" para alinhar a autopercepção de minoria discriminada com o peso político já adquirido por meio da mobilização eleitoral das últimas décadas) e "hegemonia" podem se combinar? Num entendimento clássico, leninista, de hegemonia como imposição de um projeto vitorioso por via eleitoral ou revolucionária sobre toda a sociedade, não há nada no discurso das lideranças pentecostais entrevistadas que autorize essa conclusão. Assim o reiterado debate sobre o "projeto pentecostal" como uma espécie de modelo neoconstantiniano ou neogenebrino ${ }^{7}$ de fusão entre autoridade religiosa e autoridade política é, no mínimo, equivocado.

O que aproxima, em nossa interpretação, o sentimento pentecostal de injunção à atuação política da questão da hegemonia é uma compreensão gramsciana desta última, como resultado de um complexo processo de conquistas de esferas de influência social, cultural e política, relida 
à luz de contribuições pós-estruturalistas. Isto não significa, nem pressupõe, que os atores assumam ou explicitem essa leitura.

A releitura que propomos realça os seguintes elementos: a) a política não se joga apenas na esfera da representação de interesses, mas também na construção de uma direção intelectual e política da sociedade em termos "culturais"; b) essa direção envolve a ocupação de espaços e a disseminação de um discurso que seja capaz de se apresentar ao mesmo tempo como demanda de um setor social específico e como interpelação ao apoio de outros setores, traduzindo suas respectivas demandas numa "linguagem comum"; c) a viabilização estratégica dessa construção hegemônica, ao contrário do que pensava o próprio Gramsci, já não abrange um conteúdo de classe específico, podendo ser exercida a partir dos espaços conquistados e "confinada" a eles, numa figuração multiescalar e multidimensional do poder que já não se confunde com o Estado-nação, por vezes envolvendo conexões claramente transnacionais e globais; d) embora o Estado seja obviamente um desses pontos nodais de disputa, a conquista de espaços hegemônicos nem sempre se traduz em termos de controle direto e, nas democracias contemporâneas, a pluralidade de atores e demandas provoca uma contínua alteração das fronteiras que definem esferas de "jurisdição" e exercício do poder estatal (cf. Laclau, 2005; Glynos e Howarth, 2007).

Como veremos a seguir, em torno do debate sobre religião e Estado emergem vertentes do discurso pentecostal que apontam ora para a injunção à política por motivos de sobrevivência, ora por motivos de "guerra de posições" à Gramsci. Trata-se, no primeiro caso, de resistir ao assédio dos movimentos sociais, à discriminação pela mídia, à continuidade dos privilégios desfrutados pela Igreja Católica etc. No segundo, da hegemonização como tentativa de permear "a política" ou "a sociedade" com os "valores do Reino de Deus", a partir de uma presença em múltiplos regimes de práticas - a construção da identidade (individualização), a família, a cultura (nos sentidos de entretenimento, pensamento e artes), a economia, o governo, o sistema de justiça. Enquanto os reclamos de direitos de cidadania se articulam à dignidade de ser "filho de Deus" na luta dos pentecostais para não serem invisibilizados e excluídos, a imagem de serem "sal da terra" e "luz do mundo" traduz muito bem o que aqui chamamos hegemonia (e do que para alguns pentecostais se trataria de "salvar o que está perdido"). Um de- 
putado estadual pelo Partido Socialista Brasileiro (PSB) expressa essa confluência assim:

A religião tem a ver com a política, porque a Bíblia diz que nós, homens e mulheres cristãos, são [sic] o "sal da terra e a luz do mundo". O que é sal? Sal é pra salgar o que está apodrecendo, e o mundo tá podre, a cada minuto que passa o mundo apodrece mais. Quando entra, você ou eu, com o nome de Jesus, com o brilho de Jesus, as trevas têm de ir cedendo, porque a luz vai chegando. [...] A única coisa que justifica eu estar deputado é porque eu sacudo a Bíblia e digo "eu sou crente, eu sou crente em Jesus". Porque eu não sei fazer projeto, eu não sou doutor. Eu até tenho um bocado de projeto. Mas pra mim a parte maior, mais forte do meu mandato é dizer que eu sou um milagre, eu sou um servo de Deus, foi Deus que me botou no parlamento, só ele me tira daqui.

Essa leitura não é universalmente compartilhada entre os pentecostais. Há embates internos sérios, como já ressaltamos anteriormente. A necessidade de "separação" entre religião e Estado é afirmada de várias maneiras. Para uns, como veto a que a Igreja, como instituição, apoie ou rejeite um político ou um partido:

É extremamente problemático a Igreja se pronunciar a favor ou contra um político. Porque a Igreja precisa manter a sua distância profética de qualquer partido ou figura política. Por quê? Nenhum partido e nenhuma figura encarnará plenamente os valores escriturísticos. Isso é impossível. Nem mesmo um evangélico! Porque os evangélicos são os piores exemplos!

Para alguns parlamentares, essa separação significa também a possibilidade de alinharem-se com as posições de seus partidos e tornarem-se mais autônomos em relação às lideranças eclesiásticas. Isso pode mesmo ser articulado em termos da clássica distinção liberal entre público e privado, que define a religião como "questão de foro íntimo", que "dá os elementos básicos para que nós tenhamos uma conduta correta", mas não se afirma publicamente em termos institucionais.

Mas a percepção, para muitos líderes pentecostais, de uma ameaça "secularista", oriunda de avanços feitos por outros setores minoritários e por plataformas políticas libertárias, anima a tentativa de articular uma resposta ou uma defesa de valores religiosos considerados majoritários na sociedade brasileira (a ideia "hegemonizante" de representar um Brasil cristão). Aqui se expressa bem a articulação da dimensão 
da sobrevivência com a da hegemonia: os evangélicos não se veem autorizados a desobedecer as leis, mas estas estão sendo mudadas por força de mobilizações sociais e conquistas hegemônicas de outros setores da sociedade, com implicações que suscitam problemas morais para os pentecostais: como obedecer ao que não é "bíblico"? Nestas circunstâncias, a justificativa para a politização se reforça. Ela serve para conter o avanço do "secularismo" e, ao mesmo tempo, permitir que a espiritualidade pentecostal não se veja dividida entre sua autoimposta aquiescência à lei instituída e sua aspiração a uma correspondência entre a lei e as práticas favorecidas pela comunidade de fé:

Eu não posso como cidadão evangélico, assembleiano, dizer: "não vou cumprir esta Lei, porque ela está contrária à minha formação cristã". Eu terei que cumprir, senão vou sofrer as penas da Lei... Então, nós conseguimos convencer uma boa parte da Igreja da necessidade de nós estarmos aqui, porque na democracia manda quem tem mais, quem tem mais influência, quem tem mais voto, quem tem mais poder.

Novamente, trata-se de uma relação entre religião e política, não de imbricação ou fusão entre religião e Estado. A política pentecostal, nesse sentido, não tem um "projeto" de conquista do Estado e sim articula uma aspiração de hegemonia como busca de permear espaços. Não podemos perder a dimensão potencialmente contraditória dessa construção discursiva, pois ela traduz tanto a diferença entre o discurso pentecostal e um discurso liberal clássico como a existência de embates internos ao pentecostalismo entre vertentes mais liberal-conservadoras e vertentes mais cívico-republicanas.

Por outro lado, na articulação dessa estratégia de sobrevivência, o recurso às alianças táticas com setores de outras religiões e não religiosos, a utilização da mobilização eleitoral e a negociação no âmbito da grande política para garantir limites à agenda que articula o mesmo tema dos direitos em um sentido mais libertário são indicativos do caráter hegemônico dessa mesma estratégia: "Então, isso nos preocupou muito. E aí nós fizemos um grande movimento, e dentro desse movimento houve inclusive entre um turno de eleição e outro, uma grande negociação com a atual presidente da República, e essa negociação redundou, eu diria, num suporte muito forte para a eleição dela".

A dimensão hegemônica desse processo não configura um projeto abrangente preexistente. Os embates em torno da fundamentação jurídica de um projeto de lei (PL) criminalizando a discriminação com 
base na orientação sexual, o PL 122, o argumento pentecostal do suposto preconceito contra os evangélicos e as múltiplas intervenções de pastores, juristas e líderes leigos evangélicos sobre o tema da homossexualidade como conduta, identidade ou característica genética, não são a ponta do iceberg, nem a expressão de um projeto. São um lugar de manifestação do agonismo em que se veem implicados os pentecostais no contexto de temas importantes da agenda sociopolítica brasileira. A agenda não foi formulada por eles e sua intervenção tem sido mais reativa do que propositiva.

No processo de articular a defesa dos chamados valores tradicionais da família e da moralidade, no contexto da defesa da liberdade de consciência e de expressão, os pentecostais vêm se esforçando, contudo, para construir articulações ora estratégicas, ora táticas, exibindo assim as características de uma forma hegemônica de fazer política. As intervenções de alguns entrevistados revelam o esforço para "desconstruir" as bases de sustentação do movimento anti-homofobia e desqualificar o argumento de que se trata de intolerância religiosa, discriminação ou puro veto conservador dos legisladores evangélicos.

\section{"CIDADÃO DO REINO, CIDADÃO DA PÁTRIA"}

Assim como foram identificadas novas e distintas concepções de política entre os pentecostais, foram registradas avaliações díspares da atuação política dos evangélicos nos últimos anos. A heterogeneidade dessas avaliações advém em parte da própria visão que estes entrevistados têm da cultura política brasileira e do que conta como político, mas não se pode ignorar o fato de que quase um terço da amostra dos entrevistados já exerceu ou ainda exerce mandato político em uma ou mais instâncias do Poder Legislativo no país. Neste sentido, podemos dizer que os líderes que mais enfatizam os aspectos positivos da inserção dos atores pentecostais nas instâncias de poder político e apresentam mais claramente a pretensão de interferir no controle do ordenamento social brasileiro são justamente aqueles que tiveram ou ainda apresentam vínculos diretos ou indiretos com o Poder Legislativo.

Antes de entrarmos neste balanço sobre a atuação recente dos atores políticos deste segmento religioso, no entanto, é preciso esclarecer que foram identificadas quatro posições diferentes no que se refere à participação dos evangélicos nos cargos eletivos da política brasileira: a) uma defende que, como qualquer outra minoria ou segmento social, os 
evangélicos podem e devem participar das disputas pelos poderes Executivo e Legislativo; b) outra entende que esta participação deve se restringir apenas ao Poder Legislativo; c) uma terceira é contra a inserção dos irmãos de fé na política porque o "processo político brasileiro é deteriorado"; d) a última veta a participação dos grupos religiosos nestes espaços de poder por entender que o Estado é laico e por ser crítica ao messianismo ou à visão "de estabelecer um reino cristão no Brasil." As duas últimas posições são minoritárias e podem ser lidas como expressão, uma, do que há de continuidade com a tradição pentecostal de apartamento da vida política nacional, e a outra, do reconhecimento da pluralidade da sociedade e dos direitos de outras minorias.

Entre nossos entrevistados a posição mais frequente, entretanto, foi a que destaca a importância da presença dos pentecostais no Parlamento brasileiro, uma vez que é nesta esfera que ocorre a disputa dos diferentes projetos societários ou, em outras palavras, a luta pelo controle dos tipos de sociabilidade a serem institucionalizados no país. De acordo com um dos entrevistados,

O Executivo já tem as leis, tem os programas e ele vai executar. Agora, a nossa vocação é outra. É de alguém que vai trabalhar no Legislativo porque ali é debate de valores, é embate ideológico, é onde se define pra onde caminha a sociedade... Eu não estou ali pra governar ou legislar para todos. Eu estou ali representando o grupo que me representa. Agora, no cargo majoritário não, eu sou o governador de todos, eu sou o prefeito de todos.

Com um discurso fundado na representação de sua coletividade enquanto uma minoria social, os líderes que expressam esta posição favorável à representatividade do grupo no Congresso Nacional justificam o abandono da tradicional atitude de rejeição à política com argumentos de caráter pragmático e/ou ideológico. As explicações de cunho pragmático enfatizam as possibilidades de encaminhamento das demandas da comunidade confessional, como isenção fiscal para templos e o fim da dependência do grupo em relação aos políticos profissionais não evangélicos. Já as justificativas de caráter mais ideológico salientam as contribuições que os evangélicos podem dar ao processo de organização da sociedade brasileira. Nesta perspectiva, um pastor da Assembleia de Deus declarou:

Se a Bíblia diz que sou sal e luz na terra, eu tenho que contagiar e iluminar. Como é que eu, sendo luz, posso deixar que esse país fique por con- 
ta da corrupção e dos corruptos e não dou a minha participação como evangélico? Eu necessariamente tenho que ter uma atuação [...]. A igreja evangélica influenciou e vai influenciar cada vez mais. E a hora que der, nós vamos fazer um presidente da República evangélico. Não por ele ser evangélico, mas sim por ele ser o melhor. Nós também temos proposta pra melhorar esse país...

De modo geral, observou-se uma tendência dos entrevistados associarem a corrupção à cultura política brasileira que foi gestada a partir da colonização ibérica e católica que contrastaria com a cultura das formações sociais com predominância dos grupos protestantes ${ }^{8}$. Neste tipo de discurso, enquanto o ethos pentecostal é associado à honestidade, ao trabalho duro e à seriedade, a cultura política do país é descrita como "cheia de vícios", marcada pelo "jeitinho", e capaz de desvirtuar "das suas funções os homens tementes a Deus que se envolvem com a política", tornando-os gananciosos e preocupados apenas com o interesse pessoal ou da própria igreja. Ou seja,

os políticos evangélicos são tentados às mesmas práticas negativas da política: fisiologismo e a busca de interesses pessoais ou da instituição que ele representa [sic]. Então, é muito difícil ele ver a coletividade, mas isso não é problema dos políticos evangélicos, é dos políticos em geral! E o jogo político no qual o evangélico entra é aquele ali. E ele acaba sendo cooptado pelo sistema. E se ele tentar ser diferente fica uma luta de Davi contra Golias. (...) Ser relevante como evangélico nesse meio é um grande desafio pra esses políticos evangélicos.

Por assumir essa representação negativa da cultura política da sociedade inclusiva é que uma parcela pequena dos líderes que se posicionam favoráveis à presença dos evangélicos no Parlamento sugere restringir esta participação aos leigos de suas comunidades. Um dos líderes entrevistados fez a seguinte declaração:

Fui muito crítico ao envolvimento de pastores na política e isso fechou a porta à participação dos membros [leigos] na política. De uns tempos pra cá nós estamos tentando mudar, e incentivando os jovens a se envolverem e se filiarem a um partido político para fazerem influência lá. Pra que a gente possa descobrir vocações, membros que possam exercer amanhã uma posição relevante mediante formação, treinamento e supervisão da igreja. Se eu estivesse no Congresso, eu ia propor uma lei que incluísse uma regra: "nenhum sacerdote, independente da religião, pode concorrer aos cargos". 
O envolvimento de atores políticos evangélicos nos escândalos econômicos e casos de corrupção no primeiro governo do Partido dos Trabalhadores (PT) acabou por contrariar o discurso dos religiosos sobre a restauração da ética na política, que teve um papel importante nos pleitos realizados na primeira metade da década passada. Vinte e oito políticos que integravam a Frente Parlamentar Evangélica na 52a Legislatura da Câmara Federal foram investigados pela Comissão Parlamentar de Inquérito instalada no Congresso Nacional para analisar o envolvimento dos políticos nos escândalos, e isso foi amplamente explorado pela mídia nacional (Meireles e Pereira apud Campos, 2010) ${ }^{9}$. Em decorrência disso, o número de parlamentares evangélicos na Câmara Federal sofreu um declínio de 71 para 46 na 53a Legislatura (Baptista, 2009:417-419).

Ainda que tenha reconquistado cadeiras no Parlamento no ano de 2010, com a eleição de 69 evangélicos para a Câmara Federal, a presença de autoridades pentecostais provocou abalos na construção discursiva que contrastava a identidade pentecostal com a dos brasileiros não evangélicos, e fez com que alguns entrevistados fossem bastante críticos aos legisladores que entraram na vida política a partir do púlpito e/ou com apoio das igrejas. Por exemplo, neste posicionamento:

Existem duas vertentes diferentes: uma, ingênua, parte do pressuposto de que se tivermos um grande número de políticos nós vamos fermentar o Brasil para Cristo. "Quando for de Jesus, o Brasil vai ser um país mais justo". [...] É só moralismo. A grande maioria se elege em cima deste discurso moralista, sem a mínima discussão política. Já a outra vertente é meramente oportunista: "Nós temos que ter lá uma pessoa para que os nossos interesses estejam bem representados, para que a gente possa acionar no dia que precisar de alguma benesse". E é sempre se espelhando na Igreja Católica. Eles dizem: a Igreja Católica conseguiu dois milhões para um projeto social, por que a gente não consegue também?

Como sugere a citação acima, e outras entrevistas corroboram-na, a concepção de participação política que fundamenta a maior parte dos grupos pentecostais é restrita à representação da minoria religiosa no âmbito do poder do Estado e, em especial, na gestão do bem público, reforçando a lógica corporativa já presente na cultura política brasileira, com o que um dos entrevistados chamou de "corporativismo denominacional". A maioria dos políticos evangélicos é "composta de meros meninos de recado dos seus pastores", nos declarou outro pastor. 
Este discurso via de regra vem dos entrevistados ligados ao modelo de que a politização pentecostal deve se dar pela sociedade civil e precisa ser aprofundada. Neste sentido é preciso mencionar que houve profundas mudanças não só na atitude social quanto aos pentecostais, mas na própria mobilidade social destes. No início da década de 1980, um grande número ainda provinha diretamente do mundo rural ou era a primeira geração urbana de filhos de migrantes rurais. Era um contingente de pouca escolaridade, nenhuma experiência de participação social e política significativa e uma teologia que desestimulava tanto esses envolvimentos como qualquer leitura "estrutural" de questões de poder, classe social, pobreza, racismo ou desigualdade de gênero.

As mudanças profundas trazidas pelas últimas décadas levaram ao surgimento de uma geração mais escolarizada e profissionalizada, com maior acesso ao consumo, e também uma crescente capacidade de olhar criticamente para dentro (de suas tradições de fé) e para fora (condições sociais e políticas vigentes). Mas essa geração ainda se depara com uma liderança centralizadora e que não acompanhou no mesmo ritmo e intensidade aquelas mudanças. Ainda persistem temas-tabu e visões defendidas por pastores pentecostais de que não cabe à igreja fazer "trabalho social".

A literatura brasileira indica que, embora alguns evangélicos tenham se envolvido com a luta pelo fim do autoritarismo e restabelecimento da democracia no país, a maioria dos grupos que integram o segmento pentecostal apoiou as forças militares (Freston, 2011 e 2004; Burity e Machado, 2006; Machado, 2006; Martin, 2006) e praticamente não teve vínculos com os movimentos sociais que gestaram o "projeto democratizante e participativo" nos anos de 1980 e 1990 do século passado com o objetivo de expandir a cidadania e aprofundar a democracia (Dagnino, 2005). Consequentemente, o aprendizado da gramática política e das regras que regem o sistema partidário nacional vem sendo feito de forma acrítica, com os legisladores pentecostais reproduzindo os modelos tradicionais de ação política.

Encontramos também em quase metade dos entrevistados uma autocrítica da experiência dos pentecostais no poder. No primeiro caso, alguns destacam a pressão que a geração mais jovem está realizando sobre os políticos evangélicos com o objetivo de torná-los mais responsáveis perante os eleitores evangélicos e para a sociedade em geral. Ou- 
tros apresentaram uma crítica neoanabatista (rejeição de qualquer fusão entre Igreja e Estado) da política baseada unicamente no Estado, destacando as bases, a vocação local do compromisso de caridade da Igreja e a necessidade de preservar uma voz profética para ela. No segundo caso, entrevistados que são ativistas sociais criticam a fragilidade do ethos político pentecostal (seu corporativismo, orientação autorreferente e sua reprodução dos vícios da cultura política dominante), mas também questionam até que ponto as igrejas são pratica e teologicamente consistentes em demonstrar seu compromisso social com os pobres e discriminados.

Analisando a politização dos evangélicos na América Latina, Martin (2006:34) argumenta que "os pentecostais na política são estranhos à classe política, frequentemente pertencendo à cultura do pastorado, e são sempre potenciais clientes num mundo permeado por pressupostos católicos". Martin sugere ainda que o engajamento político dos pentecostais no plano nacional torna-se problemático para as igrejas quando os legisladores se envolvem em casos de corrupção, mas este não seria um problema só deste segmento social. Acrescentamos que basta lembrar que importantes dirigentes do PT foram condenados à prisão pelo Supremo Tribunal Federal num processo que pôs em jogo a credibilidade do próprio partido.

De qualquer maneira, pode-se dizer que a entrada em cena desses novos atores políticos, mais do que ajudar na superação, tem contribuído para a reprodução das lógicas patrimonialista, personalista, autoritária e clientelística presentes na cultura política brasileira. Pode-se argumentar também que a percepção restrita de participação política da maioria dos líderes pentecostais entrevistados apresenta afinidades eletivas com o projeto neoliberal de Estado mínimo que nas últimas duas décadas travou uma forte disputa com o projeto democratizante participativo na sociedade brasileira. A começar pelo entendimento da cidadania que, como no projeto neoliberal, se ancora na participação no mercado de trabalho e de bens e consumo, encontramos também afinidade entre a proposta de transferência das responsabilidades sociais do Estado para a sociedade e o empenho de vários dirigentes pentecostais em fazer parcerias com a máquina estatal e participar das políticas públicas no país. A pouca transparência no recrutamento dos parceiros pelo Estado, a falta de uma política de avaliação dos serviços prestados e a dificuldade da sociedade civil em acompanhar as prestações de conta das organizações e/ou fundações criadas com este pro- 
pósito vêm despertando apreensão entre os setores mais progressistas da sociedade.

\section{CONSIDERAÇÕES FINAIS}

O exame das concepções de política e das avaliações da própria liderança pentecostal sobre a representação parlamentar desse segmento confessional indica uma clara percepção de um momento assertivo. Sugere ainda avanços significativos no âmbito das dinâmicas socioculturais (conversões em massa, impacto da mídia, algumas evidências de ativismo social relacionado com o modelo de representação social não parlamentar), juntamente com as exigências de representação política, reconhecimento e garantia de direitos. Percebe-se uma complexa e contraditória articulação das concepções pentecostais da política com o contexto mais amplo do liberalismo, apresentando a política como um recurso institucional e cultural em geral, mas não se pode ignorar o impacto dos recentes avanços da política de esquerda no discurso de várias lideranças.

Por um lado, enquanto a tradicional rejeição do mundo pode informar críticas às práticas políticas atuais, a falta de socialização política (devida tanto ao sectarismo quanto aos repetidos períodos de regime autoritário na sociedade brasileira) torna eleitores e representantes pentecostais vulneráveis aos mais perniciosos aspectos da cultura política brasileira. Há também, na esteira do enorme impacto do neopentecostalismo sobre a espiritualidade e a identidade evangélica, uma aceitação ambígua do empreendedorismo neoliberal (Burity, 2013) e um foco na representação social de interesses e na desregulamentação dos controles estatais sobre a economia, que se chocam com as políticas de bem-estar implementadas pelo Estado no pós-2002.

Estimulando a politização, este contexto coloca novos desafios ao pentecostalismo: neste cenário difícil, líderes pentecostais sentem que devem entrar na política como um meio de defender o planeta contra as pressões secularistas (religião pública), mas também fazê-lo de maneira que apontam para uma forma hegemônica da política. Eles lutam pela sobrevivência na esfera pública e, portanto, precisam "controlar" as suas expectativas na presença de outros atores que devem convencer ou com quem devem negociar - sejam aqueles que procuram resistir à mudança, sejam os que pretendem aprofundar a democratização e a pluralização. Neste contexto, pode-se perceber uma proposta genérica 
de criação de uma sociedade cristã (o chamado "projeto pentecostal") à espreita sob certas afirmações triunfalistas, mas isso não é consistente e abrangente o suficiente para materializar-se como uma alternativa de pleno direito.

Existem inúmeros obstáculos e desafios enfrentados pelos pentecostais brasileiros nessa trajetória. Alguns advêm das próprias características do Pentecostalismo como um movimento religioso: sua pluralização, disseminação para além das fronteiras denominacionais; sua teologia narrativa baseada em interpretações "leigas", ad hoc, da Bíblia; a identidade sectária mantida até recentemente etc. Outros desafios surgem como resultado de pressões na esfera sociocultural mais ampla - o consumismo, o individualismo, o desenvolvimento de movimentos sociais que carregam exigências de "secularização" - assim como os confrontos com setores da mídia secular e da política institucional. Muitos pentecostais ressentem-se de uma socialização política consistente que poderia prepará-los para os desafios da pluralização para além de sua retórica bíblica. Daí a percepção de "atraso" dos pentecostais, identificado por um deputado social-democrata do Estado de São Paulo: "Parece que está sempre atrasado, sempre. Depois que todo mundo saiu da sala, ainda estamos lá!" Em busca de um "passaporte para a cidadania", os pentecostais precisam pular fases e, nesse processo, tornam-se suscetíveis às influências da política antiga (elitismo, patrimonialismo, manipulação) e aos ataques dos adversários.

Os atores políticos pentecostais perdem credibilidade quando reproduzem ou retrocedem nas práticas vigentes de representação de interesses, fortemente rejeitadas pela maioria da população. Eles perdem público quando centram suas intervenções nas questões morais e na defesa corporativista de bens públicos para comunidades de fé. Eles, finalmente, perdem a oportunidade de articular uma "agenda de transformação social, quer para o país, o estado ou o município" (o mesmo parlamentar acima). Há muitos, inclusive pentecostais, que não acreditam na capacidade dos evangélicos de elevarem-se à altura do desafio de enfrentar os graves problemas da pobreza, da desigualdade e do patrimonialismo na política brasileira, dada a desmobilização local, a insensibilidade de muitos ou o envolvimento em práticas ilícitas de líderes religiosos eleitos com apoio de igrejas.

Observamos também uma grande preocupação em estar em sintonia com as grandes transformações vividas pela sociedade brasileira no 
período pós-1980, em especial com a democratização e a pluralização. Algumas podem ser identificadas na metade dos entrevistados. Já há sinais dessas tendências no comportamento eleitoral dos fiéis pentecostais, que parecem ter se tornado mais cuidadosos e seletivos na escolha dos candidatos evangélicos e um pouco mais preocupados com o monitoramento de sua participação em eventos políticos importantes. Além disso, parece haver um sentimento crescente, pelo menos entre a liderança mais jovem do pentecostalismo brasileiro, de autocrítica e engajamento em diferentes áreas da vida social, política, econômica e cultural, deixando a porta aberta para novas histórias.

(Recebido para publicação em julho de 2013)

(Reapresentado em janeiro de 2014)

(Aprovado para publicação em maio de 2014) 


\section{NOTAS}

1. As igrejas protestantes históricas são aquelas que se instalaram no Brasil durante o século XIX, seguindo a liberdade religiosa incremental para os não católicos. Batistas, presbiterianos, metodistas, congregacionais e luteranos representam os principais grupos desta categoria.

2. Sobre constantinismo, podemos dizer que se trata da transformação em tendência histórica da oficialização do cristianismo como religião de Estado e da consequente interpenetração entre autoridade religiosa e política da administração dos assuntos públicos, originadas pela conversão do imperador romano Constantino, no quarto século da Era Comum. Desde então, as várias modalidades de proximidade ou fusão legal ou política entre cristianismo e Estado têm sido classificadas como "constantinismo" ou "neoconstantinismo".

3. Os sem religião também cresceram, passando de $4,8 \%$ para $7,4 \%$, em 2000 , e $8,0 \%$, em 2010 (IBGE, censos demográficos de 2000 e 2010).

4. Dos 17 parlamentares do PRB na atual legislatura da Câmara Federal, 12 são da IURD e entre os 17 parlamentares eleitos pelo PSC, em 2010, para a Câmara Federal, 9 são ligados à $\mathrm{AD}$.

5. Associada à contribuição de Giddens (1983:1-17), essa expressão é usada aqui num sentido diferente: a) invertemos a direção do exercício da reflexividade, uma vez que os agentes religiosos podem usar as ciências sociais para interpretar sua própria prática; b) o processo se refere à postulação de um domínio de sentido próprio de uma visão religiosa do mundo, que desdobra o real numa textura em que dimensão sócio-histórica se entrelaça com a espiritual, sem que se admita se tratar de uma entre outras perspectivas. Na dupla hermenêutica, ambos os procedimentos referem-se a um mesmo real, multidimensional.

6. Entre os anos 1950 e 1960, houve um episódio de politização que expressa exatamente este segundo tipo, com o engajamento de pentecostais em movimentos pela reforma agrária (Novaes, 1985). Esta experiência permanece, entretanto, como uma espécie de memória subversiva da politização de leigos e não é vista como uma estratégia de atuação para a política institucional.

7. O modelo "neogenebrino" refere-se à modalidade de aproximação entre religião e Estado inspirada na atuação de João Calvino em Genebra, nos primórdios da reforma protestante do século XVI da qual ele foi um dos principais líderes. Enquanto o constantinismo tem forte conotação monárquica, o modelo genebrino era republicano, mas fortemente sujeito à autoridade religiosa.

8. No pensamento social brasileiro, existe uma vertente sociológica que enfatiza a permanência dos tipos de sociabilidade que marcaram o período colonial, dificultando o desenvolvimento das instituições e dos princípios igualitários que caracterizam a modernidade (Tavolaro, 2005).

9. Desse grupo, 14 eram bispos ou pastores da IURD, 10 pertenciam à Igreja Assembleia de Deus, dois à Igreja do Evangelho Quadrangular, um era Batista e o outro era integrante da Igreja Internacional da Graça de Deus. 


\section{REFERÊNCIAS BIBLIOGRÁFICAS}

BAPTISTA, Saulo. (2009), Pentecostais e Neopentecostais na Politica Brasileira. São Paulo, AnnaBlume.

BAQUERO, Marcelo. (2003), “Capital Social y Cultura Política en Brasil: Posibilidades y Límites”. América Latina Hoy, no 33, pp. 157-177.

BIRMAN, Patrícia. (2003), "Imagens Religiosas e Projetos para o Futuro", in P. Birman (ed.), Religião e Espaço Público. São Paulo, Attar Editorial, pp. 235-255.

BURITY, Joanildo. (2013), “Entrepreneurial Spirituality and Ecumenical Alterglobalism: Two Religious Responses to Global Neoliberalism", in T. Martikainen e F. Gauthier (eds.), Religion in the Neoliberal Age: Political Economy and Modes of Governance. Farnham, Ashgate/AHRC-ESRC Religion and Society Series, pp. 21-36.

(2006a), "Religião, Voto e Instituições Políticas: Notas sobre os Evangélicos nas Eleições 2002", in J. A. Burity e M. D. C. Machado, Os Votos de Deus: Evangélicos, Politica e Eleições no Brasil. Recife, Massangana, pp. 173-213.

(2006b), Religião, Redes e Participação Religiosa nas Politicas Sociais no Brasil. Recife, Massangana.

(2002), "Cultura e Cultura Política: Sobre Retornos e Retrocessos". Revista de Ciências Sociais, vol. 33, no 1, pp. 7-31.

e ANDRADE JÚNIOR, Péricles (eds.). (2011), Religião e Cidadania. São Cristóvão/Recife, UFS/Fundação Joaquim Nabuco.

BURITY, Joanildo A. e MACHADO, Maria das Dores Campos (orgs.). (2006), Os Votos de Deus: Evangélicos, Política e Eleições no Brasil. Recife, Massangana.

CAMPOS, Leonildo Silveira. (2010), “O Projeto Político de 'Governo do Justo': Os Recuos e Avanços dos Evangélicos nas Eleições de 2006 e 2010 para a Câmara Federal”. Debates do NER, vol. 2, no 18, pp. 39-82.

CANNELL, Fenella. (2010), "The Anthropology of Secularism". Annual Review of Anthropology, vol. 39, pp. 85-100.

CARVALHO, José Murilo de. (2000), “Cidadania na Encruzilhada”, in N. Bignotto (org.), Pensar a República. Belo Horizonte, UFMG Editora, pp. 105-130.

CASANOVA, José. (2010), "Religion Challenging the Myth of Secular Democracy", in L. Christoffersen et al. (eds.), Religion in the 21 $1^{\text {st }}$ Century: Challenges and Transformations. Farnham/Burlington, Ashgate, pp. 19-36.

. (1994), Public Religions in the Modern World. Chicago, University of Chicago.

CORTEN, André; DOZON, Jean-Pierre e ORO, Ari Pedro (eds.). (2003), Les Nouveaux Conquérants de la Foi: L'Église Universelle du Royamme de Dieu (Brésil). Paris, Karthala.

DAGNINO, Evelina. (2005), "Políticas Culturais, Democracia e o Projeto Neoliberal". Revista Rio de Janeiro, no 15, pp. 45-63.

DOMBROWSKI, Daniel A. (2001), Rawls and Religion: The Case for Political Liberalism. Albany, State University of New York. 


\section{Maria das Dores Campos Machado e Joanildo Burity}

FERNANDES, Rubem César et al. (1998), Novo Nascimento: Os Evangélicos em Casa, na Igreja e na Política. Rio de Janeiro, Mauad.

FONSECA, Alexandre Brasil. (2008), "Religion and Democracy in Brazil: A Study of the Leading Evangelical Politicians", in P. Freston (ed.), Evangelical Christianity and Democracy in Latin America. Oxford, Oxford University Press, pp. 163-206.

FRESTON, Paul. (2011), "Religious Pluralism, Democracy and Human Rights in Latin America", in T. Banchoff e R. Wuthnow (eds.), Religion and the Global Politics of Human Rigths. Oxford, Oxford University Press, pp. 101-127.

. (2008), "Researching the Heartland of Pentecostalism: Latin Americans Home and Abroad". Fieldwork in Religion, vol. 3, no 2, pp. 122-144.

(2004), Protestant Political Parties: A Global Survey. Aldershot, Ashgate.

(1999), "Neo-Pentecostalism' in Brazil: Problems of Definition and the Struggle for Hegemony". Archives de Sciences Sociales des Religions, vol. 44, no105, pp. 145-162.

GIDDENS, Anthony. (1983), "Hermeneutics and Social Theory”, in Profiles and Critiques in Social Theory. Berkeley/Los Angeles, University of California Press, pp. 1-17.

GLYNOS, Jason e HOWARTH, David. (2007), Logics of Critical Explanation in Social and Political Theory. Abingdon/New York, Routledge.

HABERMAS, Jürgen. (2008), "Religion in the Public Sphere: Cognitive Presuppositions for the 'Public Use of Reason' by Religious and Secular Citizens", in Between Naturalism and Religion. Cambridge/Malden, Polity, pp. 114-147.

LACLAU, Ernesto. (2005), On Populist Reason. London, Verso.

MACHADO, Maria das Dores Campos. (2012), "Religião, Cultura e Política”. Religião e Sociedade, vol. 32, no 2, pp. 29-56.

(2006), Política e Religião. Rio de Janeiro, FGV Editora.

. (2003), “Neopentecostalismo: Continuidades e Descontinuidades nas Representações e Relações de Poder entre os Gêneros". Caminhos, vol. 1, no 2, pp. 67-82.

MARIANO, Ricardo. (2005), “Pentecostais e Política no Brasil”. ComCiência, no 65. Disponível em http://www.comciencia.br/reportagens/2005/05/13.shtml. Acesso em 30 de dezembro de 2012.

(2000), Neopentecostais: Sociologia do Novo Pentecostalismo no Brasil. São Paulo, Loyola.

MARTIN, David. (2006), “Undermining the Old Paradigms, Rescripting Pentecostal Accounts". PentecoStudies, vol. 5, no 1, pp. 18-38.

. (2002), Pentecostalism: The World their Parish. Oxford, Blackwell.

NOVAES, Regina Reyes. (1985), Os Escolhidos de Deus: Pentecostais, Trabalhadores e Cidadania. Rio de Janeiro, Marco Zero/Cadernos do ISER, no 19.

ORO, Ari Pedro. (2011), "Algumas Interpelações do Pentecostalismo no Brasil”. Horizontes Antropológicos, vol. 9, no 22, pp. 383-395.

. (2010), "Ascension et Déclin du Pentecôtisme Politique au Brésil". Archives de Sciences Sociales des Religions, vol. 149, pp. 151-168. 
(2003), “Organização Eclesial e Eficácia Política: O Caso da Igreja Universal do Reino de Deus". Civitas: Revista de Ciências Sociais, vol. 3, no 1, pp. 97-109.

SMILDE, David. (2004), “Contradiction without Paradox: Evangelical Political Culture in the 1998 Venezuelan Elections". Latin American Politics and Society, vol. 46, no 1, pp. 75-102.

SORJ, Bernardo. (2006), A Nova Sociedade Brasileira. Rio de Janeiro, Jorge Zahar.

STEWART-GAMBINO, Hanna e WILSON, Evelyn. (1997), “Latin American Pentecostals: Old Stereotypes and New Challenges", in E. L. Cleary e H. W. StewartGambino (eds.), Power, Politics and Pentecostals in Latin America. Boulder, Westview.

TAVOLARO, Sérgio B. F. (2005), “Existe uma Modernidade Brasileira? Reflexões em torno de um Dilema Sociológico Brasileiro". Revista Brasileira de Ciências Sociais, vol. 20, no 59, pp. 5-22. 


\section{RESUMO}

A Ascensão Politica dos Pentecostais no Brasil na Avaliação de Líderes Religiosos

Este artigo analisa a percepção de líderes pentecostais sobre a política brasileira e a atuação dos legisladores deste segmento confessional nas últimas três décadas. Após uma breve apresentação das principais transformações ocorridas a partir da redemocratização do país nas esferas política e cultural, examinam-se as opiniões destas lideranças sobre a importância da política no contexto contemporâneo e a relação dos grupos religiosos com esta esfera. Em seguida, discute-se a avaliação destes líderes acerca do comportamento parlamentar dos pentecostais. À guisa de conclusão, argumenta-se que embora existam concepções diferenciadas de política, predomina a visão minimalista da participação política. Sugere-se também que é hegemônica a ideia de que, como toda e qualquer minoria, este segmento religioso tem que se fazer presente nas instâncias de poder para influenciar no ordenamento da sociedade.

Palavras-chave: opiniões; cultura política; liderança religiosa; pentecostalismo brasileiro

\section{ABSTRACT \\ The Political Rise of Pentecostals in Brazil in the Eyes of Religious Leaders}

This article offers an analysis of the perception of Pentecostal leaders on Brazilian politics and the performance of Pentecostal legislators over the last three decades. After providing a brief presentation of the main transformations undergone by the Brazilian society since redemocratisation at the political and cultural levels, the authors look into those leaders' views on the importance of politics in the contemporary context and on the relationship between religious groups and the political sphere. The evaluation made by such leaders of Pentecostals' parliamentary behavior is then discussed. By way of conclusion, it is argued that despite different conceptions of politics, a minimalist view of political participation prevails. It is also suggested that there is a hegemonic idea according to which - as happens with any minority this religious segment must seek to get a foothold within the seats of power in order to influence how society is ordered.

Keywords: opinions; political culture; religious leadership; Brazilian Pentecostalism 


\section{RÉSUMÉ}

L'Ascension Politique des Pentecostaux au Brésil dans l'Évaluation des Leaders Religieux

Il s'agit d'une analyse de la perception de leaders pentecostaux sur la politique brésilienne et l'action des legislateurs de ce segment confessionel pendant les trois dernières décennies. Après une brève présentation des principales transformations qui ont eu lieu à partir de la redémocratization du pays dans les sphères politique et culturelle, nous examinons les opinions de ces leaderships sur l'importance de la politique dans le contexte contemporain et la relation des groupes religieux avec cette sphère. Ensuite, on discute l'évaluation de ces leaders sur le comportement parlementaire des pentecostaux. En guise de conclusion, on soutien l'argument - malgré l'existence des conceptions differenciées de politique - qu'il y a une prédominance de la vision minimaliste de participation politique. On propose aussi que c'est hégémonique l'idée que, comme toute et n'importe quelle minorité, ce segment religieux doit être présent dans les instances de pouvoir pour avoir influence sur l'organisation de la société.

Mots clés: opinions; culture politique; leadership religieux; pentecostalisme brésilien

\section{RESUMEN}

El Ascenso Político de los Pentecostales en Brasil en la Evaluación de Líderes Religiosos

El presente artículo analiza la percepción de los líderes pentecostales sobre la política brasileña y la actuación de los legisladores de este segmento confesional en las últimas tres décadas. Tras una breve presentación de las principales transformaciones ocurridas a partir de la redemocratización del país en las esferas política y cultural, se examinan las opiniones de estos líderes acerca de la importancia de la política en el contexto contemporáneo y la relación de los grupos religiosos con dicha esfera. Enseguida, se discute la evaluación de estos líderes sobre el comportamiento parlamentario de los pentecostales. A modo de conclusión, se argumenta que aunque existan concepciones diferenciadas de política, prevalece la visión minimalista de participación política. Asimismo, se sugiere que existe una hegemonía de la idea de que este segmento religioso, como cualquier minoría, se hace presente en las instancias de poder para influenciar en el ordenamiento de la sociedad.

Palabras clave: opiniones; cultura política; liderazgo religioso; pentecostalismo brasileño 